\title{
Long-term outcomes of patients bridged to recovery versus patients bridged to transplantation
}

\author{
Emma J. Birks, FRCP, PhD, ${ }^{\text {a,b }}$ Robert S. George, MRCS, ${ }^{a}$ Ashi Firouzi, RN, ${ }^{c}$ Gavin Wright, FRCA, \\ Toufan Bahrami, FRCS, ${ }^{\mathrm{c}}$ Magdi H. Yacoub, FRS, ${ }^{\mathrm{b}}$ and Asghar Khaghani, FRCS $^{\mathrm{d}}$
}

Objective: The proportion of patients who can be bridged with left ventricular assist devices to myocardial recovery and the long-term outcome of these patients is unknown.

\begin{abstract}
Methods: We investigated the outcomes of patients bridged to recovery compared with those bridged to transplantation. All left ventricular assist devices were implanted as a bridge to transplantation with a very proactive program of promoting myocardial recovery. A total of 40 patients were bridged to recovery and 52 to transplantation. Of the bridged to recovery (explanted) group, 33 were men (age, $32.8 \pm 11.8$ years), 37 had dilated cardiomyopathy (familial in 3, peripartum cardiomyopathy in 3 ) and 3 had myocarditis. Of the bridged to transplantation (transplanted) group, 42 were men (age, $42.3 \pm 12.5$ years; $P<.0005$ vs bridged to recovery). The diagnosis was ischemic heart disease in 24 , dilated cardiomyopathy in 21 (only 13 received drug therapy), hypertrophic obstructive cardiomyopathy in 2, arrythmogenic right ventricular dysplasia in 2, myocarditis in 1 , and congestive heart disease in 2.
\end{abstract}

Results: The survival rate was $89.9 \%, 73.9 \%$, and $73.9 \%$ and $80.4 \%, 78.3$, and $78.3 \%$ in the explanted and transplanted groups at 1, 5, and 7 years, respectively. In total, $12(23 \%)$ patients bridged transplantation either died from, or required ventricular assist device support, for primary graft failure. Of the explanted patients, 4 $(10 \%)$ subsequently required transplantation at 34, 512, 1019, and 1213 days (2 died 25 and 1867 days after transplantation and 2 were well after 1523 and 3199 days). The rate of transplant or ventricular assist device-free survival less noncardiac death for the bridged to recovery and bridged to transplantation groups, respectively, was $89.9 \%, 73.9 \%$, and $73.9 \%$ and $80.4 \%, 78.3 \%$, and $78.3 \%$ at 1,3 , and 7 years. At latest follow-up (1394 \pm 1195 days for the bridged to recovery and $1913 \pm 941$ days for the bridged to transplantation group), 5 of the bridged to transplantation patients $(9.6 \%)$ had malignancy, $34(65.4 \%)$ had hypercholesterolemia, $25(48.1 \%)$ had hypertension, and $7(13.5 \%)$ had coronary disease. The creatinine was $125.5 \pm 43.5$ vs $95.2 \pm 16.5 \mu \mathrm{mol} / \mathrm{L}$ for the bridged to transplantation and bridged to recovery groups $(P<.001)$.

Conclusions: The outcome after explantation for myocardial recovery is comparable, if not better than, after bridge to transplantation. (J Thorac Cardiovasc Surg 2012;144:190-6)

Myocardial recovery from advanced heart failure after left ventricular assist device (LVAD) support can occur ${ }^{1-4}$; however, the incidence is generally considered low and the degree of recovery rarely thought sufficient to allow device removal. ${ }^{5-12}$ Furthermore, device removal is often considered hazardous and the long-term outcome of patients after device removal unknown.

We have developed a strategy ${ }^{13}$ that aggressively promotes and tests for myocardial recovery in patients with advanced dilated cardiomyopathy on LVAD support using

From the Heart Science Centre, ${ }^{\mathrm{a}}$ Imperial College, Harefield, United Kingdom; University of Louisville, ${ }^{b}$ Louisville, Ky; Royal Brompton and Harefield Foundation Trust, ${ }^{\mathrm{c}}$ Harefield, United Kingdom; and Spectrum Health, ${ }^{\mathrm{d}}$ Grand Rapids, Mich. Disclosures: Authors have nothing to disclose with regard to commercial support. Received for publication Nov 7, 2011; revisions received Jan 17, 2012; accepted for publication March 12, 2012; available ahead of print April 12, 2012.

Address for reprints: Emma J. Birks, FRCP, PhD, University of Louisville, Jewish

Hospital, 10th floor, Rudd Heart and Lung Institute, 201 Abraham Flexner Way,

Louisville, KY 40202 (E-mail: e.birks@imperial.ac.uk).

0022-5223/\$36.00

Copyright (C) 2012 by The American Association for Thoracic Surgery

doi:10.1016/j.jtcvs.2012.03.021 a combination of additional specific drug therapy, ${ }^{14-17}$ combined with regular testing of underlying myocardial function with the LVAD turned off or essentially off. ${ }^{18,19}$ This strategy has resulted in a high rate of recovery in patients with chronic heart failure secondary to dilated cardiomyopathy (DCM) and has resulted in many undergoing device explantation..$^{20,21}$

The aim of the present study was first to review the effect and results of an aggressive attempt at promoting myocardial recovery in patients with advance heart failure on a total bridge to transplant program and secondly to compare the long-term outcomes of patients after device removal compared with those progressing to heart transplantation from the device as planned. This would help with future decisions regarding the aggressiveness with which recovery is promoted for such patients and the patient's decision to undergo explantation.

\section{METHODS}

A total of 195 patients received an LVAD as a bridge to transplantation (BTT) at the Royal Brompton and Harefield National Health Service Trust 


\section{Abbreviations and Acronyms \\ $\mathrm{BIVAD}=$ biventricular assist device \\ $\mathrm{BTR}=$ bridge to recovery \\ BTT = bridge to transplantation \\ DCM = dilated cardiomyopathy \\ LVAD $=$ left ventricular assist device \\ PVAD $=$ paracorporeal ventricular assist device \\ RVAD $=$ right ventricular assist device}

from the beginning of the program (January 1, 1995) to October 1, 2009. All devices were implanted as per the intended bridge-to-transplant-only government funding. During that period, of the 195 implanted patients, $83(42.6 \%)$ died, $52(26.7 \%)$ underwent transplantation, $40(20.5 \%)$ were explanted for myocardial recovery, and $20(10.3 \%)$ were ongoing. The actuarial survival rate for the overall program, censored at transplantation or explantation, was $74.7 \%, 65.8 \%$, and $56.2 \%$ at 30 days, 90 days, and 1 year, with a dramatic improvement over time. The 30-day, 90-day, and 1-year survival rate increased from $39.1 \%, 34.8 \%$, and $27.8 \%$ for the 1995 to 1998 implants to $92.7 \%, 87.3 \%$, and $76.3 \%$ for the 2006 to 2009 implants.

The 92 patients who were either transplanted $(\mathrm{n}=52)$ or explanted for myocardial recovery $(n=40)$ were the subjects of the present study. Their preoperative demographics, hemodynamics, and other clinical parameters were reviewed, and their clinical course on the device and long-term outcomes after either transplantation or explantation were studied. This cohort was followed up for at least 30 days after transplantation (range, 594-4226; mean, $1913 \pm 941$ ) or explantation (range, 30-3451; mean, $1394 \pm 1195$ ). The patient records, charts, and our prospectively recorded databases were reviewed.

\section{Patients Bridged to Recovery}

Of the initial cohort bridged to transplantation, 40 were explanted during the study period after achieving sufficient improvement in myocardial function to be judged explantable (ie, were "bridged to recovery"). Of these, 33 were men (age, $32.8 \pm 11.8$ years; range, $15.7-58.3$ years). Of the 40 patients, 37 had nonischemic DCM and 3 had myocarditis (Figure 1). Of the 37 patients with DCM, 3 had familial cardiomyopathy and 3 had postpartum cardiomyopathy. Two patients had a biventricular assist device (BIVAD) Levitronix (Thoratec, Pleasanton, Calif) for 26 and 58 days and 1 had extracorporeal membrane oxygenation for 6 days before long-term device implantation (originally deemed too ill for long-term device implantation). The preoperative details are listed in Table 1. Of the patients who recovered, 18 had had a Heartmate I LVAD (Thoratec), 15 a Heartmate II (Thoratec), 3 a Jarvik 2000 (Jarvik Heart, New York, NY), 1 a Heartware (HeartWare International, Framington, Mass), and 3 were bridged directly to recovery with a Levitronix device.

Five patients (12.5\%) also required additional right ventricular assist device (RVAD) support-1 Heartmate I patient required a Thoratec RVAD (removed after 61 days) and 2 Heartmate I and 2 Heartmate II patients required a Levitronix RVAD (removed at $26.5 \pm 19.7$ days).

\section{Patients Bridged to Tranplantation}

Although all patients were implanted as a bridge to transplantation, 52 patients were transplanted during the study period. Of the 52 patients, 42 were males (mean age, $42.3 \pm 12.5$; range, $15-59$ years at ventricular assist device [VAD] implantation). The underlying diagnoses are shown in Figure 1. Of the 52 patients, 24 had ischemic heart disease, 2 hypertrophic obstructive cardiomyopathy, 2 arrythmogenic right ventricular dysplasia, 1 transposition of the great arteries (previous Mustard), 1 small apical ventriculoseptal defects, 1 myocarditis, and 21 DCM. Of the 21 patients with DCM, 1 patient had developed DCM secondary to chemotherapy for non-Hodgkin's lymphoma and 2 had postpartum DCM.

Of the 21 patients with DCM who did not recover and were transplanted, only 13 had any treatment or testing for recovery and the other 8 had no attempt at inducing recovery ( 2 had had a short-term device, 3 had had a Jarvik 2000 at a point at which we did not have institutional review board approval to promote and test for recovery, 2 had a paracorporeal VAD (PVAD) that we did not make any attempt to recover, and 1 had a BIVAD with significant infection and hence went straight to transplantation).

One patient had a BioMedicus (Eden Prairie, Minn) and 3 a BIVAD Levitronix before their long-term device implantation. The preoperative variables are listed in Table 1. Of the patients, 21 received a Heartmate I LVAD, 1 a combined Heartmate I LVAD and Thoratec PVAD RVAD, 6 had a PVAD LVAD, 6 had a PVAD BIVAD, 8 received a Jarvik 2000 LVAD, and 6 a Heartmate II LVAD. Of these patients, 4 (7.7\%; 2 a Heartmate 1,1 a Jarvik, and 1 a Heartmate II) also received a Levitronix RVAD that was removed from 3 before transplantation. Of the 52 patients, 4 $(7.7 \%)$ were bridged directly with a Levitronix to transplantation.

\section{Statistical Analysis}

The data are expressed as the mean \pm standard deviation and the minimum and maximum, unless stated otherwise. A nonparametric Mann-Whitney $U$ test was used to compare the preimplantation clinical parameters between the BTT and BTR groups. The Kaplan-Meier method was used to calculate the freedom from death and freedom from death/ recurrence of heart failure.

\section{RESULTS}

The actuarial survival of the BTR and BTT groups is shown in Figure 2.

\section{Course With Device and Outcome of Patients BTR}

The overall duration of support for the 40 patients in the BTR group was $331.6 \pm 223.4$ days (for the 37 patients with a long-term device, $355.8 \pm 214.5$ days; for the 3 patients bridged directly to recovery with a Levitronix device, $32.6 \pm 12.1$ days).

Two Heartmate I patients and 1 Heartware patient required a device exchange during their period of support. One patient had device failure of his Heartmate I and 1 patient of his Jarvik 2000 device (lead fracture) before explantation. All patients had undergone implantation as a BTT but all were considered ready for device explantation; significant infection was also present at explantation in 6 patients and contributed to the decision to explant.

After explantation, the actuarial survival rate was $89.9 \%$, $73.9 \%$, and $73.9 \%$ at 1,5 , and 7 years, respectively (Figure 2). There were 4 early deaths $(10 \%)$. The first patient died 1 day after explantation. She had developed heparin-induced thrombocytopenia antibodies that had cleared. Thus, she received heparin for the explant that was associated with a severe bradycardic episode. She was extubated with minimal inotropic support with good ventricular function when she developed supraventricular and then intractable ventricular arrhythmias. An autopsy showed granulomas suggestive of an allergic reaction 


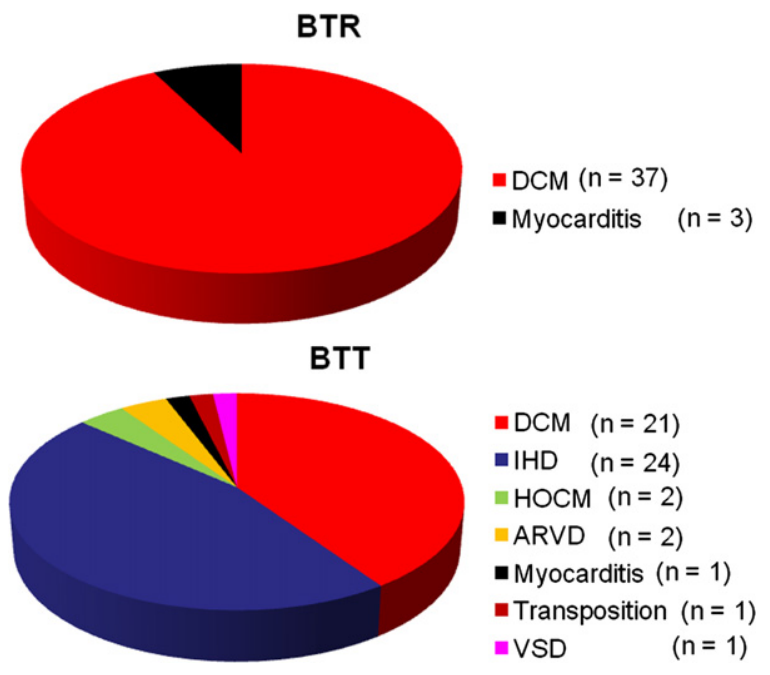

FIGURE 1. Diagnoses at implantation in bridge to recovery $(B T R)$ vs bridge to transplantation (BTT) group. DCM, Dilated cardiomyopathy; $I H D$, ischemic heart disease; HOCM, hyperobstructive cardiomyopathy; $A R V D$, arrythmogenic right ventricular dysplasia; $V S D$, ventricular septal device.

probably due to the heparin. The second patient developed recurrent heart failure a few hours after explantation; extracorporeal membrane oxygenation was implanted, but he died after 9 days. The third had excellent signs of recovery (ejection fraction, $61 \%$; left ventricular end-diastolic dimension, $41 \mathrm{~mm}$; left ventricular endsystolic dimension, $30 \mathrm{~mm}$; myocardial volume oxygen consumption, $27.4 \mathrm{~mL} / \mathrm{kg} / \mathrm{min}$; and cardiac index, 4 $\mathrm{L} / \mathrm{min} / \mathrm{m}^{2}$ ); however, transesophageal echocardiography at explantation showed new thrombus in the ascending aorta around the coronary sinuses, which had disappeared by the time the aortic root was opened and was assumed to have gone down the coronary arteries. Subsequently, it took several attempts to wean him from cardiopulmonary bypass, and a Levitronix short-term LVAD was inserted. By day 6 , he was weaning from inotropes, extubated, and no longer required hemofiltration. However, he experienced intracerebral hemorrhage and died on day 14 . The fourth patient died 26 days after explantation. He had had reasonable recovery but had had recurrent severe driveline infection (Enterobacter cloacae, Acinotabacter baumanii). After explantation, he was extubated in the operating room and initially did extremely well. However on day 3 , he was sitting out of bed opening his bowels when he became very sweaty, tachycardic, and had ventricular fibrillation arrest. He required extracorporeal membrane oxygenation insertion but had a poor neurologic recovery and died on day 26.

TABLE 1. Patient demographics before ventricular assist device implantation

\begin{tabular}{|c|c|c|}
\hline Preoperative parameter & Bridged to recovery $(n=40)$ & Bridged to transplantation $(n=52)$ \\
\hline Age (y) & $32.8 \pm 11.8^{*}$ & $42.3 \pm 12.5$ \\
\hline \multicolumn{3}{|l|}{ Gender } \\
\hline Male & 33 & 42 \\
\hline Female & 7 & 10 \\
\hline Diagnosis & $\begin{array}{l}37 \text { DCM (including } 3 \text { familial and } 3 \text { postpartum); } \\
3 \text { myocarditis }\end{array}$ & $\begin{array}{l}24 \text { IHD; } 21 \text { DCM; } 2 \text { HOCM; } 2 \text { ARVD; } 1 \text { transposition; } \\
1 \text { VSD; } 1 \text { myocarditis }\end{array}$ \\
\hline Device & 18 HMI; 15 HMII; 3 Jarvik; 1 Heartware; 3 Levitronix & $\begin{array}{l}21 \text { HMI; } 6 \text { HMII; } 1 \text { HMI and PVAD RVAD; } 12 \text { PVAD } \\
\text { (6 LVAD and } 6 \text { BIVADs); } 8 \text { Jarvik; } 4 \text { Levitronix }\end{array}$ \\
\hline IABP & $10(25 \%)$ & $27(52 \%)$ \\
\hline Ventilated & $7(17.5 \%)$ & $6(11.5 \%)$ \\
\hline Inotropes (n) & $2.0 \pm 0.8$ & $1.9 \pm 1.1$ \\
\hline Preoperative device & 2 BIVAD Levitronix; 1 ECMO & 3 BIVAD Levitronix; 1 BioMedicus \\
\hline PCWP $(\mathrm{mm} \mathrm{Hg})$ & $26.9 \pm 7.4$ & $28.8 \pm 8.9$ \\
\hline $\mathrm{CI}\left(\mathrm{L} / \mathrm{min} / \mathrm{m}^{2}\right)$ & $1.6 \pm 0.6$ & $1.5 \pm 0.3$ \\
\hline PA systolic (mm Hg) & $45.5 \pm 13.2 \dagger$ & $53.7 \pm 14.1$ \\
\hline PA mean $(\mathrm{mm} \mathrm{Hg})$ & $32.7 \pm 6.9 \dagger$ & $38.8 \pm 9.7$ \\
\hline PA saturation $(\%)$ & $42.7 \pm 12.7$ & $51.2 \pm 10$ \\
\hline Duration of heart failure $(\mathrm{m})$ & $25.8 \pm 50 \dagger$ & $42.2 \pm 44.1$ \\
\hline $\operatorname{EDD}(\mathrm{mm})$ & $70.5 \pm 11.5$ & $69.0 \pm 13.8$ \\
\hline $\mathrm{ESD}(\mathrm{mm})$ & $64.4 \pm 10.9$ & $60.9 \pm 14.2$ \\
\hline $\mathrm{EF}(\%)$ & $22 \pm 7.8$ & $25 \pm 12$ \\
\hline Creatinine $(\mu \mathrm{mol} / \mathrm{L}) \ddagger$ & $129.2 \pm 54.4($ range, $74-318)$ & $124.6 \pm 56.5($ range, $44-341)$ \\
\hline Bilirubin $(\mu \mathrm{mol} / \mathrm{L}) \S$ & $40.7 \pm 22.4$ (range, $14-99)$ & $43.2 \pm 34.9$ (range, $5-197)$ \\
\hline
\end{tabular}

Different distribution of diagnoses between groups might affect some of the other variables (eg, ventricular dimensions). DCM, Dilated cardiomyopathy; IHD, ischemic heart disease; HOCM, hypertrophic obstructive cardiomyopathy; $A R V D$, arrythmogenic right ventricular dysplasia; VSD, ventricular septal device; HM, Heartmate; $P V A D$, paracorporeal ventricular assist device; $R V A D$, right ventricular assist device; $L V A D$, left ventricular assist device; $B I V A D$, biventricular assist device; IABP, intra-aortic balloon pump; $E C M O$, extracorporeal membrane oxygenation; $P C W P$, pulmonary capillary wedge pressure; $C I$, cardiac index; $P A$, pulmonary artery; $E D D$, end-diastolic dimension; $E S D$, endsystolic dimension; $E F$, ejection fraction. ${ }^{*} P<.005 . \dagger P<.05$. $\ddagger$ Normal range, $60-110 \mu \mathrm{mol} / \mathrm{L}$. $\S$ Normal range, $5-17 \mu \mathrm{mol} / \mathrm{L}$. 


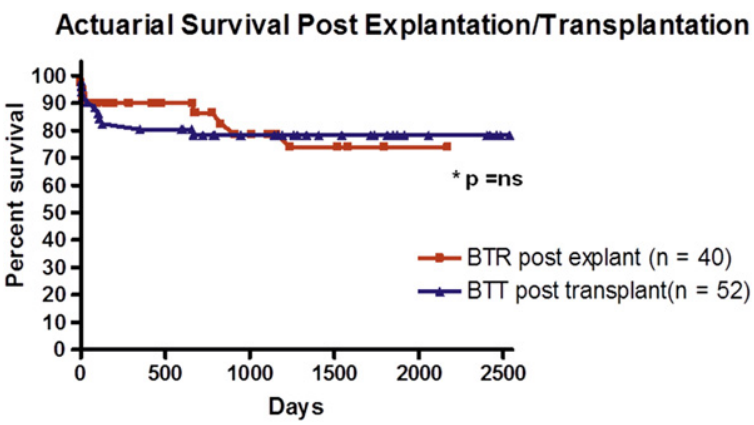

FIGURE 2. Actuarial survival of explanted $(\mathrm{n}=40)$ compared with transplanted $(\mathrm{n}=52)$ groups. $B T R$, Bridge to recovery; $B T T$, bridge to transplant.

There were 4 late deaths, 1 at 2.3 years of lung carcinoma in a smoker (who owned an English pub), 1 at 2.5 years of a paracetemol overdose (at the time of the overdose, he was physically very well, with an ejection fraction of $60 \%$ ), and 1 at 7.3 years of recurrent heart failure, principally from mitral regurgitation. The latter patient had had extremely good quality of life until 7 years after explantation; he was 63 years old at the recurrence of heart failure and decided not to undergo additional surgery. The fourth patient died 8 years after explantation at age 39 years and again had had good quality of life for 7.3 years (holding 2 concurrent active jobs). When he developed recurrent heart failure, his body mass index was $36 \mathrm{~kg} / \mathrm{m}^{2}$, and he was considered too overweight by the multidisciplinary team for transplantation or BTT.

\section{Course With Device and Outcomes of Patients BTT}

The duration of support for the 52 patients in the BTT group was $313 \pm 210$ days (for the 48 patients bridged with a long-term device, $333 \pm 206$ days; and for the 4 patients bridged directly with a Levitronix device, $73.3 \pm 33.8$ days). Two Heartmate I patients required device exchange to a PVAD and 1 PVAD patient required a device exchange during the period of support. Two patients had failure of their Heartmate I before transplantation and were maintained with the pneumatic console before urgent transplantation.

After transplantation, the actuarial survival rate was $80.4 \%, 78.3 \%$, and $78.3 \%$ at 1,5 , and 7 years, respectively (Figure 2). There were $5(9.6 \%)$ early, $5(9.6 \%)$ midterm, and $3(5.8 \%)$ late deaths. Of the 5 early deaths, 1 was in the operating room of primary graft failure, 3 were 2,3 , and 4 days after transplantation of primary graft failure (all 3 had received BIVAD support for the donor heart). The fifth was from a mixture of primary graft failure and gastrointestinal ischemia (in a patient who had had a Heartmate I) at 10 days after transplantation. Of the 5 midterm deaths, 1 died at 38 days of primary graft failure (after a period of BIVAD support for the transplanted heart, the donor histologic examination subsequently showed early hypertrophic obstructive cardiomyopathy). A second died at 82 days, a donor patent foramen ovale was closed 7 days after the transplant, precipitating donor right heart failure requiring a period of RVAD support. He ultimately died of a large hemothorax from a line insertion. The third had a significant degree of graft failure and received augmented immunosuppression, resulting in sepsis and death at 102 days. A fourth patient required BIVAD support for 5 weeks to the donor heart; however, when the BIVAD was removed, he required additional inotropic/intra-aortic balloon pump support and then developed sepsis and died at 108 days. A fifth patient required an Abiomed pump in the donor heart for primary graft failure. This was subsequently removed, but he developed pneumonia and died at 125 days. There were 3 late deaths; 1 at 1.8 years of motor neuron disease, 1 at 665 days of noncompliance, and 1 at 7.8 years of squamous cell carcinoma of the scalp.

\section{Failure of Explantation or Transplantation}

In addition to the deaths, we compared the failure of the explanted heart (ie, requiring transplantation) with failure of the transplanted heart (ie, requiring VAD support).

\section{Failure of Explanted Heart Requiring Transplantation}

Four patients $(10 \%)$ required transplantation after explantation. One Heartmate I patient had significant device-related infection at explantation and hence was very tachycardic after explantation. After 2 days of tachycardia after explantation, he developed ventricular tachycardia, the heart dilated, and he experienced cardiac arrest requiring Levitronix VAD implantation. He was transplanted 32 days later; he was alive and well 4.2 years later. Another patient with a Heartmate I device had a large abdominal infection at explantation, contributing to the decision to explant him. He did well initially but slowly developed recurrent heart failure and underwent transplantation 1.4 years later. He did well after transplantation and finally developed acute, followed by chronic, rejection and died of a pulmonary embolus 7.4 years after transplantation. A third patient did well after explantation but then had an episode of significant alcohol consumption, triggering deterioration of his cardiac function. He was transplanted 2.8 years after explantation and was alive and well 6 years after transplantation. A fourth patient remained very well for 2.5 years after tying off of the Jarvik device. She had had residual mitral regurgitation at the tying off of the device that worsened with time, developing recurrent heart failure after 2.5 years and undergoing transplantation after 3.3 years. However, she had primary graft failure requiring a BIVAD for the donor heart and died 25 days after transplantation.

The rate of freedom from death or transplantation after explantation was $89.9 \%, 69 \%$, and $69 \%$ at 1,5 , and 7 


\section{Freedom from death or transplantation post explant and from death or VAD support post transplant}

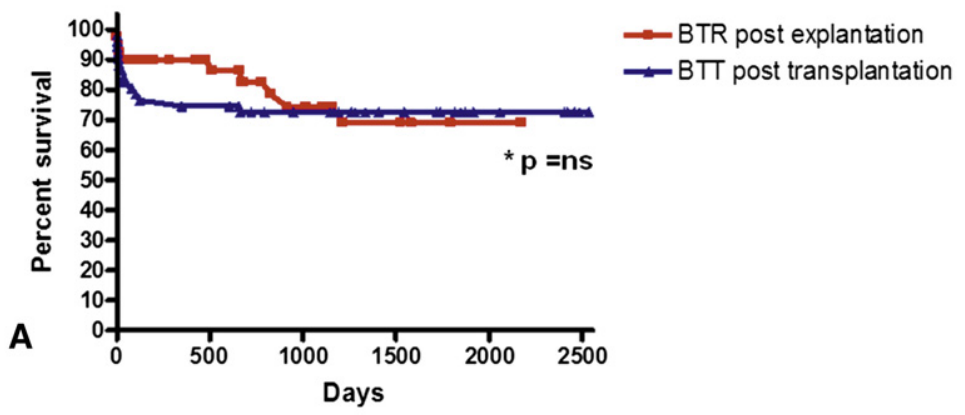

Freedom from death or transplantation post explant and from death or VAD support post transplant (less non cardiac death)

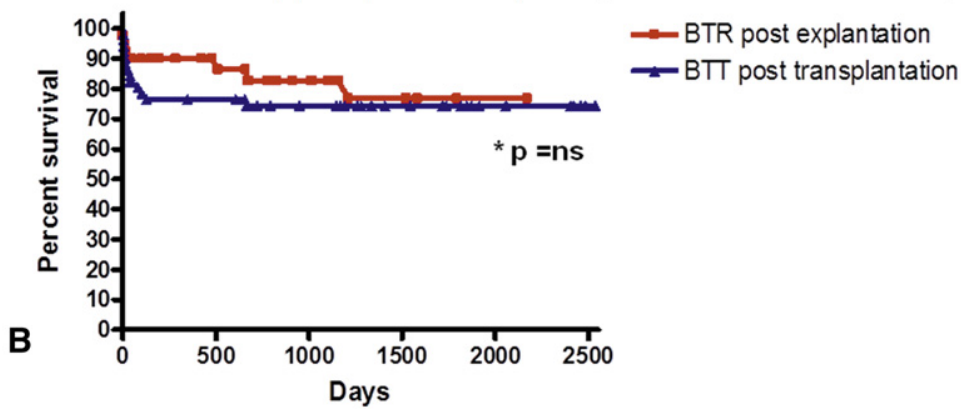

FIGURE 3. A, Freedom from death or transplantation for explanted $(\mathrm{n}=40)$ compared with death or need for ventricular assist device $(V A D)$ support for transplanted $(n=52)$ group. B, Freedom from death or transplantation for explanted $(n=40)$ compared with death or need for VAD support for transplanted $(\mathrm{n}=52)$ group, excluding noncardiac death (ie, excluding deaths from lung carcinoma and paracetemol overdose in the bridge to recovery [BTR] group and from motor neuron disease in the bridge to transplantation $[B T T]$ group). NS, Not significant.

years, respectively (Figure 3, $A$ ). The rate of freedom from death or transplantation after explantation, excluding noncardiac death, was $89.9 \%, 76.7 \%$, and $76.7 \%$ at 1,5 , and 7 years, respectively (Figure 3, B).

\section{Failure of Transplanted Heart Requiring Mechanical Support}

In total, $12(23 \%)$ of the patients bridged to transplantation had significant primary graft failure requiring mechanical support for the donor heart or resulting in the recipient's death. Eight of the deaths occurring after transplantation in the BTT group were primarily from primary graft failure (7 required mechanical support for the donor heart and 1 died of primary graft failure in the operating room). An additional 4 patients required a period of VAD support after transplantation (ie, had had primary graft failure sufficient to require a period of mechanical support for the donor heart): 2, a BIVAD for 6 and 20 days; 1 , a RVAD for 25 days; and 1, a LVAD for 14 days. The rate of freedom from death or requirement for VAD support after transplantation was $74.5 \%, 72.4 \%$, and $72.4 \%$ at 1,5 , and 7 years, respectively (Figure $3, A$ ). The rate of freedom from death or requirement for VAD support after transplantation, excluding noncardiac death, was $76.5 \%, 74.4 \%$, and $74.4 \%$ at 1,5 , and 7 years, respectively (Figure $3, B$ ).

\section{Postexplant and Post-Transplant Clinical Outcomes}

In the surviving explant patients at latest follow-up, a mean period of $1394 \pm 1195$ days (range, 30-3451) after

TABLE 2. Follow-up parameters at latest follow-up

\begin{tabular}{lcc}
\hline \multicolumn{1}{c}{$\begin{array}{c}\text { Follow-up } \\
\text { parameter }\end{array}$} & Bridged to recovery & $\begin{array}{c}\text { Bridged to } \\
\text { transplantation }\end{array}$ \\
\hline Follow-up period & $1394 \pm 1195(30-3451)$ & $1913 \pm 941(594-4226)$ \\
LVEDD (mm) & $59.4 \pm 8.4^{*}$ & $50 \pm 6.1$ \\
LVESD (mm) & $44.5 \pm 11.7^{*}$ & $32.1 \pm 6$ \\
EF (\%) & $57.4 \pm 17.4^{*}$ & $73.6 \pm 6.6$ \\
Creatinine (g/L) & $92.7 \pm 18.5 \dagger$ & $125.5 \pm 43.5$ \\
Bilirubin (g/L) & $23.7 \pm 26.2$ & $17.7 \pm 7.3$ \\
mVO 2 (mL/kg/min) & $26 \pm 6.4$ & Not done \\
Hyperlipidemia & $0(0)$ & $34(65.4 \%)$ \\
Hypertension & $0(0)$ & $25(48.1 \%)$ \\
Coronary disease & $0(0)$ & $7(13.5 \%)$ \\
Malignancy & $0(0)$ & $5(9.6 \%)$
\end{tabular}

LVEDD, Left ventricular end-diastolic dimension; LVESD, left ventricular end-systolic dimension; $E F$, ejection fraction; $\mathrm{mVO}_{2}$, myocardial volume oxygen consumption. $* P<.00005 . \dagger P<.0005$. 
explantation, the mean left ventricular end-diastolic dimension was $59.4 \pm 8.4 \mathrm{~mm}$, left ventricular end-systolic dimension was $44.5 \pm 11.7 \mathrm{~mm}$, ejection fraction was $57.4 \% \pm 17 \%$, serum creatinine $95.2 \pm 16.5 \mu \mathrm{mol} / \mathrm{L}$, bilirubin $24.6 \pm 26.9 \mu \mathrm{mol} / \mathrm{L}$ (Table 2), and myocardial volume oxygen consumption was $26 \pm 6.4 \mathrm{~mL} / \mathrm{kg} / \mathrm{min}$. No patients developed hypercholesterolemia, hypertension, coronary disease, or malignancy.

In the surviving transplant patients at latest follow-up, a mean period of $1913 \pm 941$ days (range, 594-4226 days) after transplantation, the left ventricular enddiastolic dimension was $50 \pm 6.1 \mathrm{~mm}$, left ventricular end-systolic dimension was $32.1 \pm 6.0 \mathrm{~mm}$, ejection fraction $73.6 \% \pm 6.6 \%$, creatinine was $125.5 \pm 43.5 \mu \mathrm{mol} / \mathrm{L}$, and bilirubin $17.7 \pm 7.3 \mu \mathrm{mol} / \mathrm{L}$ (Table 2). A total of $34(65.4 \%)$ transplanted patients developed hypercholesterolemia, and 25 (48.1\%) developed hypertension; 7 patients developed coronary disease, 5 of whom had only mild disease. Five patients $(9.6 \%)$ developed malignancy (1 Epstein-Barr virus-induced lymphoproliferative disease, 1 carcinoma of the esophagus, 1 renal cell carcinoma, 1 skin carcinoma, and 1 small cell carcinoma of the scalp).

\section{DISCUSSION}

We have compared for the first time the outcomes of a large cohort of patients explanted for myocardial recovery with the outcomes of patients transplanted on a device during the same period. We demonstrated the significant effect on a total mechanical circulatory support program of aggressively promoting recovery and explanting patients. We have also demonstrated comparable, if not better, survival and lower failure rates and a lower rate of longer term complications in the explanted compared with the transplanted group.

We have demonstrated the advantages and disadvantages and benefits and risks of explantation of LVADs due to sufficient myocardial recovery. The decision to explant can be very difficult ${ }^{12,22}$ owing to the paucity of data currently available. We have provided some long-term data and hope to encourage programs to attempt recovery of their patients. We have also previously demonstrated the quality of life of the explanted patients to be very good. ${ }^{23}$

Our data show a significant number of patients can be explanted if recovery is aggressively promoted and tested for, particularly patients with nonischemic cardiomyopathy. Although all patients were implanted as a BTT, only 52 patients were transplanted during this 14 -year period and 40 were explanted. Of the 21 patients with DCM who did not recover and were transplanted, only 13 had received any treatment or testing for recovery, and 8 had had no attempt at inducing recovery. In contrast, 37 patients with DCM recovered and were explanted; thus, the rate of recovery in patients with DCM at our institution with an aggressive attempt to induce remission of heart failure using drugs and testing ${ }^{18,19}$ was much greater than at other institutions to date. ${ }^{20,21}$

During the study period, of all 195 implanted patients with any diagnosis, $83(42.6 \%)$ died, $52(26.7 \%)$ were transplanted, $40(20.5 \%)$ were explanted for myocardial recovery, and $2(10.3 \%)$ were still ongoing. Hence, of the 112 survivors, $40(35.7 \%)$ were explanted, $52(46.4 \%)$ were transplanted, and $20(17.9 \%)$ were ongoing (ie, outcome unknown). This is a high proportion given that recovery was only attempted in the patients with DCM.

The number of donor organs available for transplantation is declining and is totally inadequate for the number of patients requiring transplantation. Thus, being able to explant these patients is very important because such patients could then avoid transplantation and the donor heart can be saved for another patient. This is particularly important in the United Kingdom, where funding is currently only available for inserting these devices as a BTT and not as destination therapy.

A better term than "myocardial recovery" might well be remission of heart failure. We studied the effectiveness and durability of that remission by considering the long-term follow-up of a large group of explanted patients. Survival was similar between the explanted and transplanted patients. There were 4 early deaths after explantation and 4 late deaths, 2 of which were not cardiac-related (carcinoma of the lung and paracetemol overdose) and the other 2 were very late ( $>7$ years). Of the explanted patients, 4 required transplantation, of whom 2 were alive and well at the last follow-up, 1 survived 7.4 years with his transplanted heart, and 1 died early after transplantation. The rate of failure of the transplanted hearts was greater than that of the failure of the explanted hearts (Figure 3). A striking finding was the good functional capacity of the explanted group.

Several of the patients had significant driveline infection, often contributing to the decision to explant. Infection can make these patients tachycardic and vasoplegic and they can require vasopressors, which can be detrimental to the explanted heart, as can the tachycardia. One of the early deaths appeared to be precipitated by tachycardia. We changed our strategy over time to give these patients very aggressive antibiotics (chosen according to driveline sensitivities) around explantation, to give their $\beta$-blocker on the morning of the explant to limit the tachycardia. We also developed a low threshold for hemofiltration of the patient for a short period (usually about 12 hours) with the purpose of cooling the patient and limiting the tachycardia.

In the long term, the transplanted patients started to encounter the typical complications that occur after transplantation, often related to their immunosuppression. There was a high incidence of hypertension and hyperlipidemia and a significant amount of coronary disease and malignancy. The creatinine at latest follow-up was also significantly greater in the transplanted patients. 
Myocardial recovery, particularly for younger patients, is the best option, especially as the option to reinsert the device later or transplant them later exists. It is likely that their overall lifespan would be significantly prolonged (either by explantation alone or by a combination of both). Our data also suggest that a significant number of explanted patients are likely to never need a device or heart transplant.

\section{Study Limitations}

Although many of the patients with DCM were prospectively studied as part of individual prospective studies, ${ }^{20,21}$ many others were not; thus, this was essentially a retrospective analysis, although of the entire VAD program. From December 1999 onward, all Heartmate I and Heartmate II patients with DCM received an aggressive attempt at inducing recovery, along with testing of underlying myocardial function. However, this did not occur before December 1999, and not all the patients receiving other devices received such an aggressive attempt at inducing recovery. Patients with other diagnoses did not receive either testing or promotion of myocardial recovery. Another limitation of the present study was the high rate of primary graft failure in our cohort after transplantation. There has been a $46 \%$ decline ${ }^{24}$ in the number of heart transplants in the United Kingdom during the past 10 years, causing centers to use more marginal donors and resulting in greater rates of primary graft failure in several UK centers, including ours. This might have skewed the comparison of survival after transplantation vs explantation. ${ }^{25}$

\section{CONCLUSIONS}

In conclusion, our results suggest that aggressively attempting recovery can have a major effect on a BTT program and its patients, managing to avoid transplantation in a significant proportion. The outcomes of those who are explanted were comparable, if not superior, to the outcomes of those undergoing transplantation.

\section{References}

1. Frazier OH, Radovancevic B, Abou-Awdi NL, Wilansky S, Jin B, Capek P, et al. Ventricular remodelling after prolonged ventricular unloading: "heart rest" experience with the Heartmate left ventricular assist device. J Heart Lung Transplant. 1994;13(Pt 2):77.

2. Frazier OH, Benedict CR, Radovancevic B, Bick RJ, Capek P, Springer WE, et al. Improved left ventricular function after chronic left ventricular unloading. Ann Thorac Surg. 1996;62:675-82.

3. Levin HR, Oz MC, Chen JM, Packer M, Rose EA, Burkhoff D. Reversal of chronic ventricular dilation in patients with end-stage cardiomyopathy by prolonged mechanical unloading. Circulation. 1995;91:2717-20.

4. Frazier OH, Myers TJ. Left ventricular assist system as a bridge to myocardial recovery. Ann Thorac Surg. 1999;68:734-41.

5. Levin HR, Oz MC, Cantanese KA, Rose EA, Burkhoff D. Transient normalisation of systolic and diastolic function after support with a left ventricular assist device in a patient with dialed cardiomyopathy. J Heart Lung Transplant. 1996;15:840-2.

6. Mancini DM, Beniaminovitz A, Levin H, Cantanese K, Flannery M, Di Tullio M, et al. Low incidence of myocardial recovery after left ventricular assist device implantation in patients with chronic heart failure. Circulation. 1998; 98:2383-9.

7. Farrar DJ, Holman WR, McBride LR, Kormos RL, Icenogle TB, Hendry PJ, et al. Long-term follow-up of Thoratec ventricular assist device bridge-to-recovery patients successfully removed from support after recovery of ventricular function. $J$ Heart Lung Transplant. 2002;21:516-21.

8. Simon MA, Kormos RL, Murali S, Nair P, Heffernan M, Gorcsan J, et al. Myocardial recovery using ventricular assist devices: prevalence, clinical characteristics, and outcomes. Circulation. 2005;112(9 Suppl):I32-6.

9. Muller J, Wallukat G, Weng YG, Dandel M, Spiegelsberger S, Semrau S, et al. Weaning from mechanical cardiac support in patients with idiopathic dilated cardiomyopathy. Circulation. 1997;96:542-9.

10. Maybaum S, Mancini D, Xydas S, Starling RC, Aaronson K, Pagani FD, et al. Cardiac improvement during mechanical circulatory support: a prospective multicentre study of the LVAD Working group. Circulation. 2007;115: 2497-505.

11. Dandel M, Weng Y, Siniawski H, Potapov E, Lehmkuhl HB, Hetzer R. Long-term results in patients with idiopathic dilated cardiomyopathy after weaning from left ventricular assist devices. Circulation. 2005;112(9 Suppl):I37-45.

12. Dandel M, Weng Y, Siniawski H, Potapov E, Drews T, Lehmkuhl HB, et al. Prediction of cardiac stability after weaning from left ventricular assist devices in patients with idiopathic dilated cardiomyopathy. Circulation. 2008;118(Suppl 1):S94-105

13. Yacoub MH. A novel strategy to maximize the efficacy of left ventricular assist devices as a bridge to recovery. Eur Heart J. 2001;22:534-40.

14. Wong K, Boheler KR, Bishop J, Petrou M, Yacoub MH. Clenbuterol induces cardiac hypertrophy with normal functional, morphological and molecular features. Cardiovasc Res. 1998;37:115-22.

15. Petrou M, Wynne DG, Boheler KR, Yacoub MH. Clenbuterol induces hypertrophy of the latissimus dorsi muscle and heart in the rat with molecular and phenotypic changes. Circulation. 1995;92(9 Suppl):II483-9.

16. Petrou M, Clarke S, Morrison K, Bowles C, Dunn M, Yacoub M. Clenbuterol increases stroke power and contractile speed of skeletal muscle for cardiac assist. Circulation. 1999; 99:713-20.

17. Soppa G, Smolenski R, Latif N, Yuen A, Malik A, Karbowska JK, et al. Effects of chronic administration of clenbuterol on function and metabolism of adult rat cardiac muscle. Am J Physiol Heart Circ Physiol. 2004;288:H1468-76.

18. George RS, Yacoub MH, Tasca G, Webb C, Bowles CT, Tansley P, et al. Haemodynamic and echocardiographic responses to acute interruption of left ventricular assist device support-relevance to assessment of myocardial recovery. $J$ Heart Lung Transplant. 2007;26:967-73.

19. George RS, Sabharwal NK, Webb C, Yacoub MH, Bowles CT, Hedger M, Khaghani A, Birks EJ. Echocardiographic assessment of flow across continuous-flow ventricular assist devices at low speeds. J Heart Lung Transplant. 2010;29:1245-52.

20. Birks EJ, Tansley PD, Hardy J, George R, Bowles CT, Burke M, et al. Left ventricular assist device and drug therapy for the reversal of heart failure. $N$ Engl J Med. 2006;355:1873-84.

21. Birks EJ, George RS, Hedger M, Bahrami T, Wilton P, Bowles CT, et al. Reversal of severe heart failure with a continuous-flow left ventricular assist device and pharmacologic therapy: a prospective study. Circulation. 2011;123:381-90.

22. Komoda T, Komoda S, Dandel M, Weng Y, Hetzer R. Explantation of INCOR left ventricular assist device after myocardial recovery. J Card Surg. 2008;23:642-7.

23. George RS, Yacoub MH, Bowles CT, Hipkin M, Rogers P, Hallas C, et al. Quality of life after removal of left ventricular assist device for myocardial recovery. $J$ Heart Lung Transplant. 2008;27:165-72.

24. Macgowan GA, Parry G, Schueler S, Hasan A. The decline in heart transplantation in the UK. BMJ. 2011;342:d2483.

25. Thomas HL, Dronavalli VB, Parameshwar J, Bonser RS, Banner NR. Incidence and outcome of Levitronix CentriMag support as rescue therapy for early cardiac allograft failure: a United Kingdom national study. Eur J Cardiothorac Surg. 2011;40:1348-54. 